\title{
Hypothermia in newly born piglets: Mechanisms of thermoregulation and pathophysiology of death
}

\author{
Dina Villanueva-García ${ }^{\mathrm{a}}$ | Daniel Mota-Rojas ${ }^{\mathrm{b} *}$ (i) | Julio Martínez-Burnes ${ }^{\mathrm{c}}$ (iD) | Adriana Olmos- \\ Hernández $^{\mathrm{d} \text { (D) }}$ | Patricia Mora-Medina ${ }^{\mathrm{e}}$ (D) | Cynthia Salmerón ${ }^{f}$ Jocelyn Gómez ${ }^{\mathrm{b}}$ | Luciano Boscato \\ | Oscar Gutiérrez-Pérez ${ }^{\mathrm{f}}$ | Viridiana Cruz ${ }^{\mathrm{f}}$ | Brenda Reyes ${ }^{\mathrm{b}}$ | Miguel González-Lozano
}

aivision of Neonatology, National Institute of Health, Hospital Infantil de México Federico Gómez, Mexico City, Mexico.

${ }^{b}$ Neurophysiology, behaviour and animal welfare assessment. Department of Animal Production and Agriculture, Universidad Autónoma Metropolitana, Xochimilco campus, Mexico City, Mexico.

Graduate and Research Department, Facultad de Medicina Veterinaria y Zootecnia, Universidad Autónoma de Tamaulipas, Victoria City, Tamaulipas, Mexico. 'Bioterio y Cirugía Experimental, National Rehabilitation Institute Luis Guillermo Ibarra Ibarra (INRLGII), Secretaría de Salud (SSA), Mexico City, Mexico.

eLivestock Science Department, Universidad Nacional Autónoma de México (UNAM), Facultad de Estudios Superiores Cuautitlán, 54714, State of Mexico, Mexico.

FFacultad de Medicina Veterinaria y Zootecnia (CEIEPP-FMVZ), Universidad Nacional Autónoma de México (UNAM), Ciudad de México, México.

Corresponding author: dmota@correo.xoc.uam.mx

\begin{abstract}
Mortality in piglets during the perinatal period, especially the first days after birth, is frequently caused by noninfectious conditions, such as hypoglucemia or low birth weight, which can be associated with hypothermia experienced at birth. The thermal stability of newborn piglets is a fundamental aspect of neonatal care, so maintaining a constant, ideal temperature will substantially reduce newborn mortality. Species-specific characteristics, such as a limited capacity for thermoregulation, low energy reserves, a lack of brown adipose tissue (BAT) (-, and environmental conditions that are adverse for the piglet around the time of birth, including the absence of a microclimate, all of them contribute to difficulties in reaching thermal homeostasis in the first hours post-birth. Shivering thermogenesis and behavioral modifications to regulate body temperature through innate mechanisms allow animals to reduce their energy expenditures. Some body postures are effective in reducing contact with the floor and also nestling are useful to avoid heat loss, and also decreases heat dissipation. Achieving optimal development of thermoregulation is a challenge that newborns must confront to successfully adapt to extrauterine life. The objectives of this review, are to discuss the adverse factors that can lead to a death event due to hypothermia by analyzing the thermoregulation mechanisms at the central and cutaneous levels, also to analyze the harmful impacts that surviving neonate piglets confront in an unfavorable thermal environment, and to describe the pathophysiological mechanisms of death caused by hypothermia.
\end{abstract}

Keywords brown adipose tissue, cold stress, colostrum consumption, neonate, perinatal death, shivering thermogenesis

\section{Introduction}

Perinatal mortality continues to be one of the principal problems and concerns of the pork industry (MotaRojas 1996; Mota-Rojas and Ramírez-Necoechea; 1996; Mota-Rojas et al., 2002; Mota-Rojas et al., 2006; Houška et al 2010; Martínez-Burnes et al 2019), one closely-related to issues of animal welfare (Mota-Rojas et al 2011, 2012ab). Piglets can die due to a broad range of causes, but neonatal losses attributable to cold-induced stress are rarely registered as such, although the hypothermia that results from these events can lead to starvation, crushing, and/or disease (Curtis 1974; Kelley 1985; English 1993; Herpin and Le Dividich 1995; Mota-Rojas et al 2005abc; Jensen et al 2011). Hypothermia can be a significant cause of death in neonate piglets, and although this condition is not infectious, it is considered an important factor in death on swine farms, as it may go undetected due to several natural causes (Mount 1963; Mota-Rojas et al 2011, 2012ab). Because the - newly born piglet has an immature thermoregulating center, homeostasis in its body temperature is affected within the first hours post-birth due, primarily, to the evaporation of placental fluids (Muns et al 2016; Mota-Rojas et al 2016). According to Nuntapaitoon and Tummaruk (2015), the newly born piglet is covered by approximately $23 \mathrm{~g}$ of amniotic fluid for each kilogram of live weight at birth, and about $50 \%$ of these fluids evaporate during the first 5-30 min after birth (Kammersgaard et al 2013; Muns et al 2016). For this reason, piglets experience an abrupt temperature decrease during the first hours post-birth with changes that begin from the moment of expulsion; that is, the transition from a thermoneutral, intrauterine environment to extrauterine life, an event that is accompanied by a severe reduction of the environmental temperature (ET) (approximately $15-20{ }^{\circ} \mathrm{C}$ in farrowing pens) at a very early stage of life (Herpin et al 2002; Vasdal et al 2011).

Besides, heat loss in newly born piglets is aggravated as they are born without brown adipose tissue (BAT) and with very little adipose tissue, both of which serve as insulators (Herpin et al 2002). This condition means that their only 
resource for producing heat and raising their core body temperature (CBT) consists of mobilizing energy reserves present in the form of glycogen and fat and, as a last resort, catabolizing skeletal muscle. Of course, the environmental conditions of the installations and handling around the time of birth also drastically affect the thermoregulating capacity of newly born piglets, with consequences for their survival and growth (Muns 2013). In this regard, weaker piglets are usually unable to compete successfully for colostrum and milk, and they may become hypothermic (Svendsen et al 1986). Since hypothermia and the lack of nutrition weaken them even more, problems of orientation and locomotion often follow, increasing the risk of crushing (DeRoth and Downie 1976; Svendsen et al 1986). The decrease in ET that newborn piglets experience is likely the most immediate danger they confront upon leaving the intrauterine environment (Mota-Rojas et al 2008, 2011, 2016, 2018). It is important to keep in mind, as well, that piglets are born with a high surface/volume ratio due to their small size, and that they have little hair and very little adipose tissue for use as an energy source (also, no BAT is present in them). Another condition that exacerbate this situation is that the neonate's skin is moist due to amniotic fluid (Herpin et al 2002). Hypothermia in piglets compromises various organs and systems that require additional study to fully understand the physiopathological mechanisms that lead to the death of newborn piglets by hypothermia. The objective of this review, is to discuss the adverse factors that can produce death by hypothermia in newly born piglets. To this end, we caused by non-infectious conditions, such as hypoglucemia or low birth weight, which can be associated with hypothermia experienced at birth, analyzed thermoregulation's mechanisms at the central and cutaneous levels, and the harmful effects that surviving newborn piglets face from an unfavorable thermal environment.

\section{Thermal balance and adaptation to extrauterine life}

The - newly born piglets adaptation to extrauterine life constitutes a considerable challenge for its survival and postnatal development (Baxter et al 2008) as almost immediately at birth, they experience temperatures markedly below their thermoneutral zone (Muns et al 2016). It is estimated that neonates can lose over $2{ }^{\circ} \mathrm{C}$ of body temperature (BT) between birth and their first ingestion of food (colostrum) (Tuchscherer et al 2000; Malmkvist et al 2006; Baxter et al 2008). During gestation, fetuses live at a uterine temperature that ranges from $38-40{ }^{\circ} \mathrm{C}$. However, at birth neonates suffer a drastic environmental change as they are exposed to an ET around only $20-22{ }^{\circ} \mathrm{C}$ (the temperature that coincides with the sow's thermoneutral zone) which makes them more vulnerable to stress-induced by cold (Berthon et al 1993; Tuchscherer et al 2000; Malmkvist et al 2006, 2009). Furthermore, a series of factors that include the lack of subcutaneous adipose tissue (-2\%), low glycogen reserves (Herpin et al 2002; Le Dividich et al 2005), incomplete thermoregulation, reduced insulation (Muns et al
2016), heat loss by evaporation (due to moist skin), conduction (contact with colder surfaces), radiation (scarce hair), convection (airflow), and rapid heat dissipation due to their high surface/volume ratio attributable to their size (Theil et al 2014), resulting in many piglets suffering hypothermia in the first 24 hours post-birth (Mota-Rojas et al 2008, 2011; Baxter et al 2009; Shankar et al 2009; Pedersen et al 2011) (Figure 1). One technique to evaluate farm and companion animals' surface thermal dynamics is the use of infrared thermography (IRT) (Mota-Rojas et al 2020abc; Casas-Alvarado et al 2020; Bertoni et al 2020ab). The thermal balance of newborn piglets is of primordial importance for neonatal care, so achieving and maintaining an ideal body temperature will significantly reduce perinatal mortality (Mota-Rojas et al 2008, 2011) (Figure 1). The use of IRT in both veterinary and human medicine to evaluate heat loss and gain in different corporal regions, and assess microcirculatory changes at the vascular level has proven to be effective (Küls et al 2017; Bruins et al 2018; Huggins et al 2018; Mota-Rojas et al 2020ac; Casas-Alvarado et al 2020; Bertoni et al 2020bc).

When the CBT of newborn piglets decreases to a level less than or equal to 35 으 due to the exposure to a cold environment, the result is the condition called postnatal hypothermia (Haverkamp et al 2018; Muns et al 2016). Sosnowski et al (2015) pointed out that hypothermia can occur even when all thermoregulation mechanisms are totally functional, due to an organism's prolonged exposure to cold that impedes it from taking conscious defensive measures. Lossec et al (1998), in turn, reported that hypothermia occurs naturally after birth in most mammalian neonates but that both the decrease in body temperature and the time required for recovery vary widely among different organisms. The reduction in BT accompanied by a deficit in energy ingestion are factors that weaken newborn piglets even more and, consequently, increases the risk of neonatal mortality (Alonso-Spilsbury et al 2007; Mota-Rojas et al 2011; Mota-Rojas et al 2016, 2018). Piglet survival correlates with the degree and duration of the postnatal hypothermic condition (Tuchscherer et al 2000), so newborns must adapt quickly to extrauterine life through autonomous (e.g. thermogenesis) and behavioral mechanisms for heat conservation (Kammersgaard et al 2011).

When an organism experiences slight cooling, mechanisms designed to conserve heat begin to act. However, newborn hypothermia uses up glucose reserves (in the form of glycogen) and oxygen to produce heat (Le Dividich et al 2005), which constitutes an enormous energy cost for piglets. In contrast to other mammals, - newly born piglets, especially, have a limited thermoregulation capacity during the first hours of life. Thermal homeostasis is a biological priority for all endothermal species. In the case of piglets and up to 24 hours post-birth, a temperature range of $38-39^{\circ} \mathrm{C}$ indicates thermal homeostasis (Berthon et al 1993; Herpin et al 1994).

Thermoregulation in pigs, as in other mammals, is a process orchestrated by the central nervous system (CNS) 
with the collaboration of the peripheral nervous system (PNS), through a series of autonomous and behavioral mechanisms that actively balance the production and dissipation of heat (Morrison 2016). However, the thermoregulatory response's complexity depends on the anatomical, physiological, and behavioral characteristics of a given species (Angilletta et al 2019; Tan and Knight 2018). When the newborn piglet's body temperature decreases, signals from the peripheral (cutaneous) and central (spinal cord, cerebral, visceral) thermoreceptors reach the preoptic area (POA) of the hypothalamus - through afferent pathways which process all the sensory information and activate thermoregulatory responses, also through afferent pathways (Figure 2). The POA is a thermosensitive area that regulates responses to different temperature changes and controls thermal sensitivity in the brain (Tan and Knight 2018).
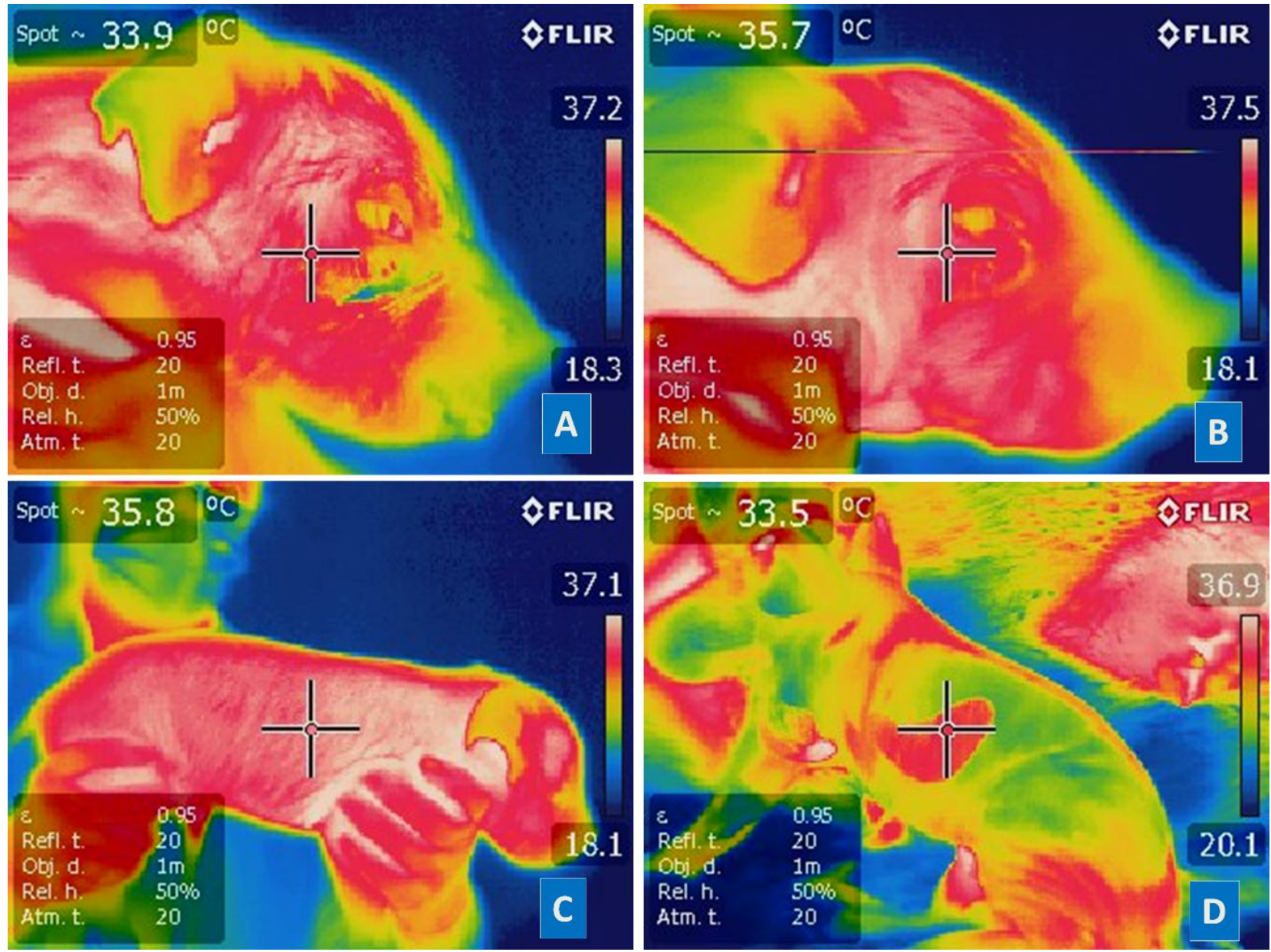

Figure 1 Newly born piglet with hypothermia. (Thermograms from the image bank of Dr. Daniel Mota Rojas). It is important to dry the newborn immediately because the moisture of the amniotic fluid favors a rapid decrease of body temperature (Mota-Rojas 1996; Mota-Rojas et al 2008, 2011, 2016). The zones marked in yellow on the thermograms indicate a temperature of $33-35^{\circ} \mathrm{C}$. Images $\mathrm{A}, \mathrm{B}$, and $\mathrm{C}$, in spite of spot is located on red zones, however please note a marked temperature decrease in surface areas of the skin and such peripheral zones as the auricular pavilions, thoracic members and, above all, the rostrum, particularly the snout (yellow zones).Thermographic image D shows a piglet with severe hypothermia over $80 \%$ of its body, despite having been dried. Piglets, therefore, must begin to suckle, or otherwise be provided with colostrum and a source of heat, in order to stabilize its thermal status and prevent consumption of hepatic glycogen (Mota-Rojas et al 2008, 2011, 2012ab, 2018).

At birth, the piglet passes from a dependent intrauterine environment to one that is independent. Hence, it must begin to regulate its body temperature to survive (Close 1992). To activate thermoregulating responses to the thermal stress caused by cold, the piglets' cutaneous (type $A \beta, A \delta$, and $C$ nerve endings) and visceral thermoreceptors perceive both absolute and relative temperature changes. These thermal stimuli cause the depolarization of thermoreceptors to generate transduction (Tan and Knight 2018). Cutaneous thermoreception is detected by the transient receptor potential (TRP) family of cation channels expressed in sensory neurons. In mammals, TRPM 8 has been detected as the primary peripheral sensor for cold (Bautista et al 2007). Afferent signals ascend through ganglia and nerve nuclei along such pathways as the cortical spinothalamic tract - and the lateral parabrachial neuronal nucleus (LPB); they are then integrated at the level of the spinal cord (Plate I, dorsal mast), encephalic trunk, and hypothalamus (Nakamura and Morrison 2008; Pitoni et al 2011; Tan and Knight 2018). Thermal stimuli are also projected to the somatosensorial cortex, which enables behavioral responses. Glutamatergic neurons are in charge of projecting the thermal information from the cutaneous, visceral, and spinal cord thermoreceptors from the LPB to the POA, where the 
information is processed (Tan and Knight 2018). The POA consists of various regions, including the medial preoptic area (MPO) and the medial preoptic nucleus (MnPO), which are considered the primary nervous structures responsible for temperature regulation (Morrison and Madden 2014; Tan and Knight 2018). Also, the POA connects to diverse brain nuclei, to maintain thermal homeostasis. Once the POA processes the thermal information, it enables the physiological responses to counteract the low temperature. This response occurs in the form of cutaneous vasoconstriction, piloerection, and/or thermogenesis (Romanovsky 2018) depending on a temperature threshold (Pitoni et al 2011). The most important physiological responses to exposure to cold are the thermogenesis of BAT and the shivering of skeletal muscle to generate heat, accompanied by constriction of the blood vessels (vasoconstriction) to prevent heat loss. Though thermogenic
BAT is considered highly necessary for thermoregulation after birth in mammal species (Mrowka and Reuter, 2016), it is not the case in pigs since there are reports that indicate that newly born piglets lack this type of tissue (Trayhurn et al 1989), and rely on shivering thermogenesis as the principal mechanism of thermoregulation (Berthon et al 1995). Reports on humans, however, suggest that shivering is less efficient than vasoconstriction as a defense against cold because much of the heat generated by peripheral muscles is released into the atmosphere instead of being retained in the core (Pitoni et al 2011). For this reason, skeletal muscle shivering generates heat, and peripheral vasoconstriction to prevent heat loss, together with piloerection that allows the formation of a layer of hot air around the body, constitute the mechanisms upon which the neonate piglet depends to reach thermal homeostasis (Figure 2).

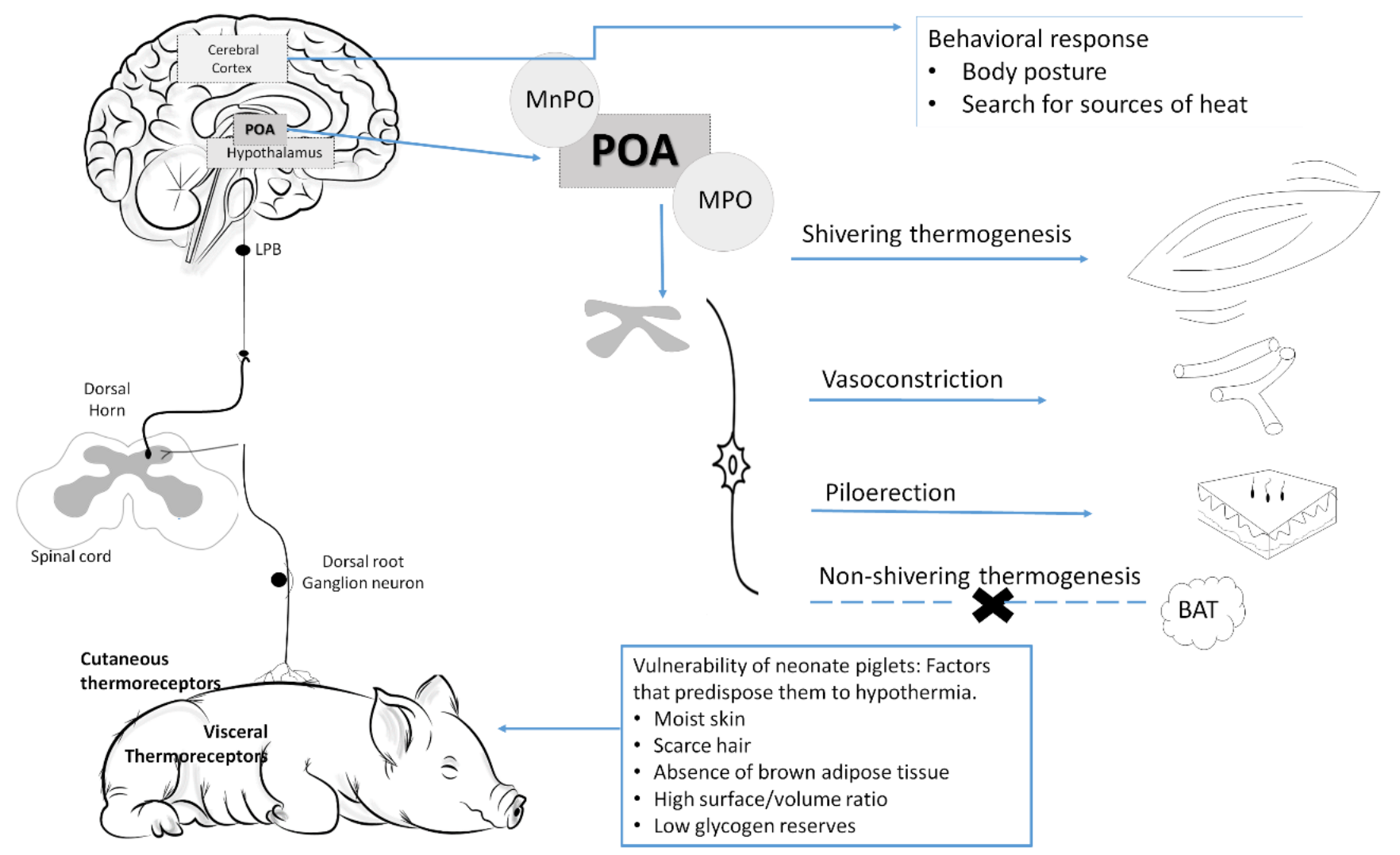

Figure 2 Neuromodulation of thermoregulation in newly born piglets. LPB: Lateral Parabrachial Nucleus. MnPO: Median Preoptic Nucleus. POA: Preoptic Anterior Hypotalamus. MPO: Medial Preoptic Area.

\section{Shivering thermogenesis}

Sow's fetuses experience constant temperature exchange through the placenta while in utero that maintains a thermostable environment. In stark contrast, the - newly born piglet is exposed to cold immediately at birth (Berthon et al 1994) and must depend on its immature thermoregulating mechanisms that were not required during intrauterine life. The essential components of thermogenesis are two fundamental mechanisms: shivering - and non- shivering thermogenesis. As mentioned above, newborn piglets have only a small amount of adipose tissue (1.5\%) and, it seems, no BAT (Herpin et al 2002). However, this situation, changes quickly with age and development, to a point where fat content reaches perhaps $15 \%$ at weaning. Studies Images $A, B$, and $C$, in spite of spot is located on red zones, however please note a marked temperature decrease in surface areas of the skin and such peripheral zones as the auricular pavilions, thoracic members and, above all, the rostrum, 
particularly the snout (yellow zones). 3-month-old piglets have also detected small amounts of tissue similar to BAT (Dauncey et al 1981).

Determining the existence of a mechanism of nonshivering thermogenesis in piglets requires measuring, simultaneously, the magnitude of shivering and the level of heat production at temperatures that run from thermoneutrality to cold (Barré et al.1985). However, the thermogenic response of newborn piglets does not include non-shivering thermogenesis. Shivering thermogenesis based on skeletal muscle, therefore, plays a major role in preserving homeothermy. Shivering thermogenesis -or simply "shivering"- refers to the production of heat through a repetitive process of muscular contraction that generates considerable amounts of heat, but rapidly consumes the newborn's energy reserves (oxidized glycogen) (Theil et al 2014; Berthon et al 1994). Shivering is considered the first line of defense against acute exposure to cold in pigs (Bal et al 2016; Berthon et al 1995). During muscular contraction, heat is generated by hydrolysis of adenosine triphosphate (ATP) from three different ATPases: ATPase of myosin, which performs the contractile work, SERCA, and $\mathrm{Na}^{+} / \mathrm{K}^{+}$ATPase (Rowland et al 2014; Little and Seebacher 2013). Studies have demonstrated the contribution of skeletal muscle to the temperature increase in average up to $97 \%$ in response to cold, in five-day-old piglets (Lossec et al 1998). Though shivering is the first response to acute exposure to cold, this reaction entails an extremely high energy cost and can even compromise muscular function (Periasamy et al 2017). Due to the absence of BAT, the newly born piglet maintains its body temperature almost exclusively by shivering (Berthon et al 1994). In this regard, free mitochondria have been detected in the skeletal muscle of two-month-old pigs adapted to cold (Herpin and Barre 1989). During muscular contraction due to cold-induced stress, a specific muscleregulating mechanism has been identified that includes the activity of the carnitine palmitotransferase I enzyme (CPT I) in the interfibrillar mitochondria. Another example is the rhomboid muscle, where CPT I's sensitivity to malonyl-CoA remains constant at ambient temperature, while the latter decreases under cold conditions. These changes could foster the oxidation of fatty acids in more oxidative muscles during shivering thermogenesis.

\section{Participation of muscular glycogen}

As the neonate pig has no BAT, its corporal reserves are essential for survival during the first hours of life, since it utilizes those glycogen and fat reserves as its primary energy substrates for producing heat in the first 12-24 hours postbirth (Berthon et al 1994). At birth, glycogen reserves at birth range from 30-35 grams per kg of body weight, and are located almost entirely in the liver and muscles. Because the piglets' subcutaneous fatty tissue is less than $2 \%$, glycogen becomes the principal energy resource. It is consumed rapidly by the piglet's metabolism to produce heat after birth by consuming segments of hepatic glycogen and $50 \%$ of the muscular tissue in just the first 12 hours of life (Charneca et al 2010). The complications that arise from having energy values (glucose) below optimal levels, combined with diminished neonatal vitality, can lead to failure when the piglet seeks to begin suckling at its dam's teat to ingest colostrum and obtain the nutrients it requires, as well as the benefit of adequate passive immunity. Also, piglets may be stressed due to hypothermia induced by hypoglycemia, which can cause them to fall into a coma quite quickly (Figure 3).

\section{Birth weight and hypothermia}

The piglet's ability to overcome postnatal hypothermia by re-establishing its body temperature after the sudden decrease during the immediate postpartum period is directly related to two aspects: birth weight (Caldara et al 2014), and its position in the corral during the first and second hours after birth. Kammersgaard et al (2011) observed that the neonate's low rectal temperature up to two hours after birth is related to birth weight of around 1.5 $\mathrm{kg}$, and to piglets that remain on the floor for more time instead of approaching the dam's udder during that time. Stanton et al (1973) also observed that the performance of newborn piglets in a cold environment is closely-related to birth weight, noting that piglets weighing 1.02-1.15 kg have a higher surface-area/body volume ratio than larger neonates with weights of $1.27-1.38 \mathrm{~kg}$., for this reason, the former are more prone to heat loss in cold environments.

\section{Thermoregulating behavior}

In addition to metabolic mechanisms, the capacity to conserve heat involves behavioral strategies. Behavioral adjustments in body posture provide efficient mechanisms for minimizing heat loss (Kammersgaard et al 2011; Bertoni et al 2020a, b; Guerrero-Legarreta et al 2020), principally because mammal species utilize specific postures to conserve energy and, in this way, limit heat dissipation. These postures reduce the surface-area/body volume ratio to minimize contact between the neonate's surface and the air and, decrease the area susceptible to heat dissipation (Terrien et al 2011). During the first day of the neonate piglet's life, physical activity is responsible for $30 \%$ of the heat production they generate. The above underscores the importance of behavioral adaptations appropriate for minimizing heat loss, and necessary for increasing heat production in unfavorable thermal conditions. Some studies have shown that piglets have one thermal advantage in this regard: heat conduction through contact with the sow's udder when they stay close to their dam for prolonged periods instead of remaining isolated. Moreover, when neonate piglets nestle or huddle with their littermates they also reduce the total surface area exposed to the low-temperature environment (Kammersgaard et al 2011; Kammersgaard et al 2013) and/or light air currents. This strategy is effective in reducing heat loss through what is called 'social' thermoregulation, since a litter of newborn piglets can increase a critically-low 
temperature -below $25-30^{\circ} \mathrm{C}$ - though this is still below their thermoneutral zone (TNZ), which is around $34^{\circ} \mathrm{C}$ (Vasdal et al 2009; Close 1992). It is important to note that nestling or huddling behaviors lessen with age and as the piglets grew, their weight increases (Vasdal et al 2009; Boon 1981).

A second strategy that piglets employ to reduce heat loss consists of adjusting their position and posture. Conductive heat loss is diminished by adopting a sternal posture from a recumbent position (Vasdal et al 2009; Mount 1967), as this allows the neonate to reduce its contact surface with the floor. There are indications that during the first and second hours post-birth, the loss of body temperature correlates with the location of the neonate piglet in the farrowing pen (Kammersgaard et al 2011); for example, when the piglet is on the floor, far from the dam's teat, its body temperature will decrease gradually (Kammersgaard et al 2011; Melišová et al 2014). In contrast, if it is close to its littermates, or the dam's udder, its body temperature will begin to rise. The above emphasizes the vital importance of behavioral adaptations by neonates to reduce heat loss. Nestling or huddling in the warmest areas of the pen also allows heat transfer by conduction from warmer objects (Kammersgaard et al 2011; Kammersgaard et al 2013). These measures allow piglets to achieve homeothermy during the first hours of life (Vasdal et al 2009; Kammersgaard et al 2011) (Figure 4).

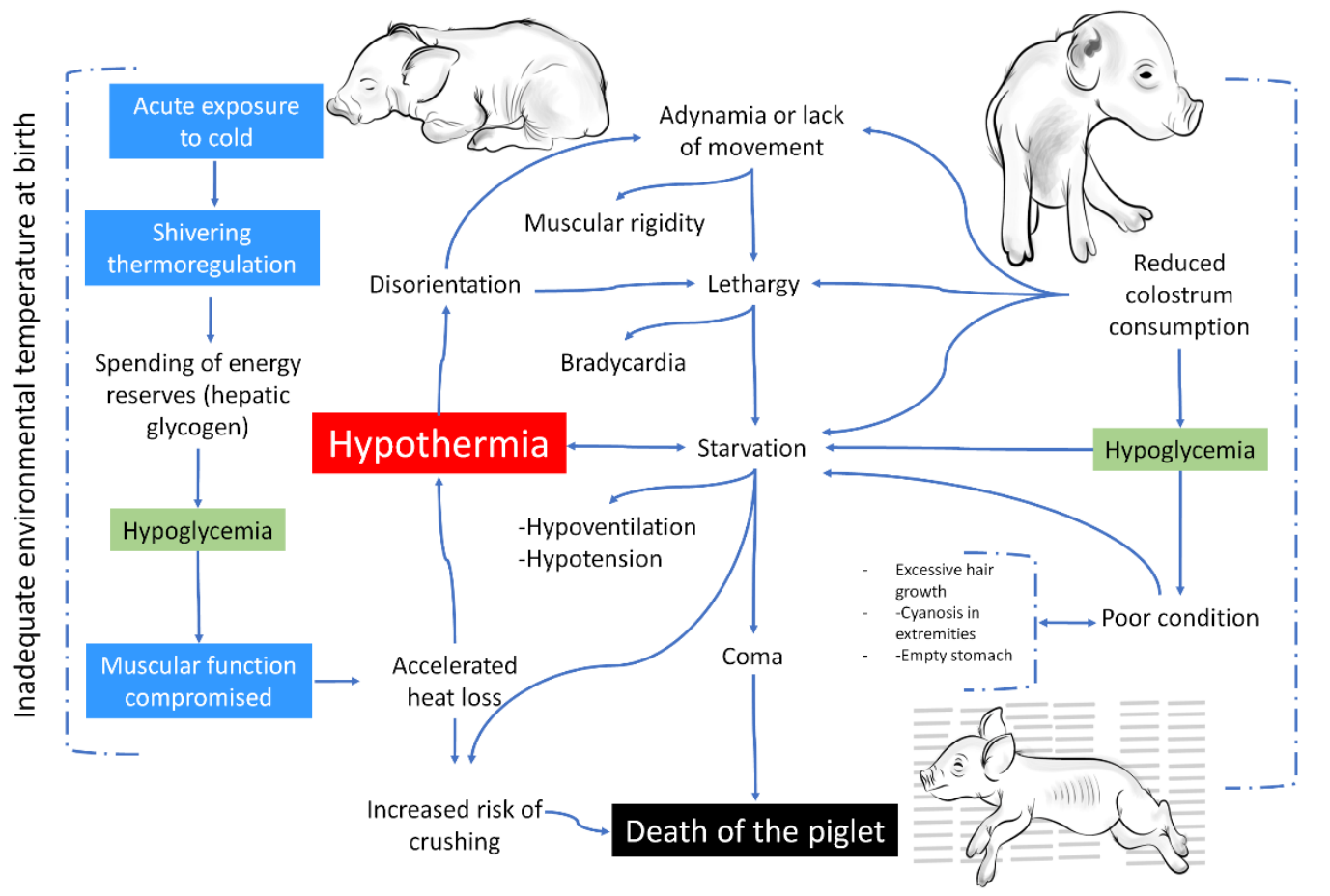

Figure 3 Factors associated with hypothermia mortality in newborn piglets.

\section{Colostrum consumption and neonatal metabolism}

The behavioral patterns that the neonate piglet adopts to generate heat include ingesting colostrum, a substance that contains the energy necessary for regulating body temperature and growth (Herpin et al 2002; Le Dividich et al 2005). Colostrum is the first milk secreted by the mammary gland, which secretes it continuously from birth to 12-24 hours postpartum (Quesnel et al 2012). At that point, milk secretion becomes cyclical and piglets fighting to access the dam's udder begins (Muns et al 2016; Auldist et al 2000). Colostrum is a rich source of digestible nutrients and several bioactive components, such as immunoglobulins (IgA, IgM and, particularly $\operatorname{lgG}$ ), hydrolytic enzymes, hormones, and growth factors (Quesnel and Farmer 2019; Baxter et al 2011; Rooke and Bland 2002; Wu et al 2010). For this reason, colostrum, plays a key role in piglet's thermoregulation, in the acquisition of passive immunity, and intestinal development and maturation (Quesnel et al 2012; Devillers et al 2007). Colostrum also supplies the newborn piglet with highly-metabolizable energy (Le Dividich and Herpin 1994) and a high content of fatty acids and lactose, which the piglet utilizes efficiently to cope with cold-induced stress by increasing its metabolic rate and maintaining homeothermic equilibrium during the first day of life (Le Dividich and Herpin, 1994). As a result, the rectal temperature of piglets at 24 hours of age correlates positively with colostrum ingestion (Muns et al 2016; Devillers et al 2011). According to Amdi et al (2017), piglets that consume colostrum within the firsthour post-birth increase their rectal temperature by $1^{\circ} \mathrm{C}$ compared to those that do not have access to colostrum (37.5 ${ }^{\circ} \mathrm{C}$ vs. $\left.36.6{ }^{\circ} \mathrm{C} ; \mathrm{P}<0.001\right)$. In other words, the piglet's body temperature increases because colostrum provides large amounts of fat (30-40\%) and can generate up to $60 \%$ of the energy that the neonate requires on its first day of life (Caldara et al 2014). Moreover, it activates the secretion of powerful lipases in the oral cavity (lingual lipase) (Theil et al 2014) that ensure the adequate degradation of the fats in the 
colostrum, making them easily digestible (Rooke and Bland 2002) and available to generate energy through glycogen oxidation (Herpin et al 2002; Theil et al 2014). In this sense, we consider that the degree at which the neonate increases its ingestion of colostrum, it increases heat production and so becomes capable of maintaining constant body temperature (Caldara et al 2014; Devillers et al 2011) therefore increasing its probability of survival.

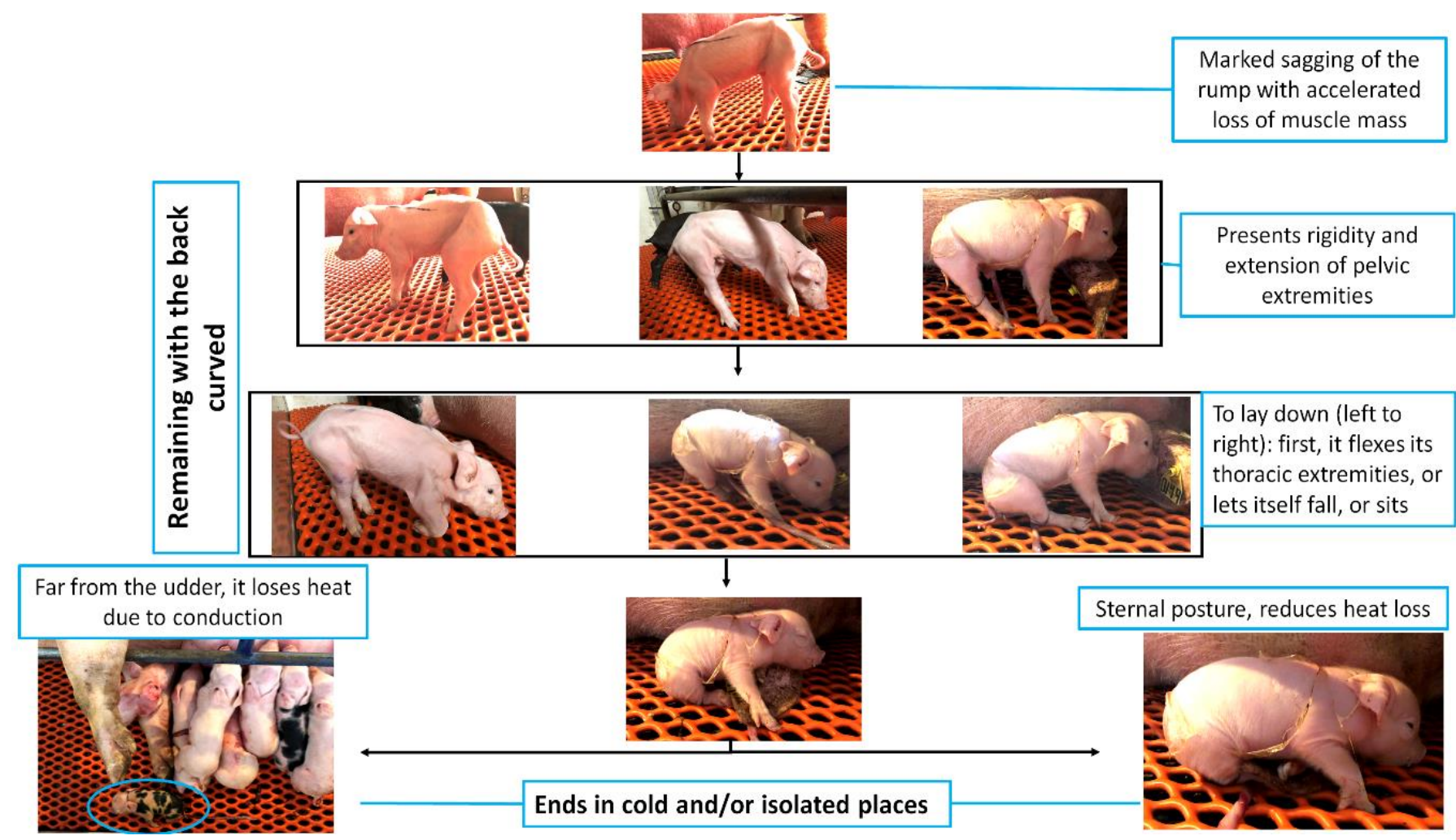

Figure 4 Physical and postural aspects of hypothermic newborn piglets.

\section{Physiopathology of death by hypothermia in farm animals}

Under normal conditions, the thermoreceptors in the skin and hypothalamus send nerve impulses to the preoptic region and the heat promoting center of the POA of the hypothalamus. The nerve impulses in the sympathetic nerve that reach the adrenal medulla stimulate the release of adrenaline and noradrenaline into the bloodstream. The nerve impulses from the heat promoting center, in turn, stimulate sympathetic nerves that cause constriction of the blood vessels in the skin to reduce the flow of warm blood, thus producing heat loss by organs internal to the skin (CasasAlvarado et al 2020). The causes of heat loss in piglets' range from cold-induced stress to an inadequate environment to metabolic diseases such as hypoglycemia, suprarenal insufficiency, hypothyroidism, or malnutrition (Mota-Rojas et al 2020a). Also, as relevant factors are the low-birth-weight and birth order, those piglets born at the end of parturition, in which the long time of the first contact with the udder of the dam and the intake of colostrum to generate heat is limited (Caldara et al 2014 Mota-Rojas et al 2008). Low-birthweight piglets are weak, and it is challenging to stand and reach the dam's heat protection, complicating the heat loss (Le Dividich and Herpin 1994; Kammersgaard et al 2011). These piglets suffer starvation, hypoglycemia, hypothermia, and eventually are crushed or die. Hypoglycemia, in turn, and the limited glycogen reserves of the newborn piglets leads to the use of hepatic or muscular glycogen conducting to metabolic acidosis. If piglets are born under perinatal asphyxia episodes, circulatory changes and hypoxia occur. Piglets are very susceptible to hypoxia, inducing nervous disorders that difficult orientation and piglets' motion to reach the udder or the dam's heat environment. Depending on the degree of the decrease in body temperature, hypothermia may be accompanied by the following effects: a sensation of cold, shivering, disorientation, vasoconstriction, muscular rigidity, bradycardia, metabolic acidosis, hypoventilation, hypotension, loss of spontaneous movement (Mota-Rojas et al 2020c), and coma, possibly ending with death which, under these circumstances, is almost always caused by cardiac arrhythmias (Figure 4). Often, the piglets that die from hypothermia have a poor corporal condition, while animals that survive a long period of hypothermia develop very long hair. Another symptom that may appear is cyanosis in the animal's extremities (Mota-Rojas et al 2016). These dead piglets are found to have empty stomachs and, therefore, low levels of blood glucose and hepatic glycogen that contribute to death by hypoglycemia (Mota-Rojas et al 2008; Mota-Rojas et al 2015; Mota-Rojas et al 2018). 


\section{Final Considerations}

The transition from intrauterine to extrauterine life in newly born piglets is accompanied by a significant reduction of environmental temperature of as many as $15^{\circ} \mathrm{C}$. One of the consequences of this situation is a drastic descent of the newborn's body temperature that may fall to a critical minimum level. Heat loss effectuated by mechanisms like conduction, convection, evaporation, and radiation, added to certain innate characteristic of this species -scarce subcutaneous adipose tissue, lack of BAT, and limited glycogen reserves- are contributing factors that can result in many piglets suffering hypothermia during the first 24 hours postpartum. For this reason, regulating the body temperature of newborn piglets -a process governed by the CNS- depends primarily on producing heat through shivering thermogenesis, as the first line of defense, supported by thermoregulating behaviors. However, for neonates exposed to cold to achieve thermal homeostasis, they must spend their reserves of hepatic and muscular glycogen. Thus, it is important to ensure adequate ingestion of colostrum, which plays a vital role in providing the energy that piglets require to achieve thermoregulation. However, hypoglycemia, is not the only effect that is considered as a risk factor for hypothermia, as low birth weight also threatens the neonate piglets' welfare. If hypothermia persists, piglets will suffer starvation leading to imminent death. In summary, the survival of neonate piglets results from the interaction between the dam, the piglet itself, and the environment.

\section{Conflict of Interest}

The authors declare that they have no conflict of interest.

\section{Funding}

This research did not receive any financial support.

\section{References}

Alonso-Spilsbury M, Ramírez-Necoechea R, González-Lozano M, Mota-Rojas D, Trujillo-Ortega ME (2007) Piglet survival in early lactation: a review. Journal of Animal and Veterinary Advances 6:76-86.

Amdi C, Jensen L, Oksbjerg N, Hansen C (2017) Supplementing newborn intrauterine growth restricted piglets with a bolus of porcine colostrum raises rectal temperatures one degree Celsius. Journal of Animal Science 95:2968-2976.

Angilletta MJ Jr, Youngblood JP, Neel LK, VandenBrooks JM (2019) The neuroscience of adaptive thermoregulation. Neuroscience Letters. 692:127136.

Auldist DE, Carlson D, Morrish L, Wakeford CM, King RH (2000) The influence of suckling interval on milk production of sows. Journal of Animal Science 78:2026-2031.

Bal NC, Maurya SK, Singh S, Wehrens XH, Periasamy M (2016) Increased Reliance on Muscle-based Thermogenesis upon Acute Minimization of Brown Adipose Tissue Function. Journal of Biological Chemistry 291:1724717257.

Barré H, Geloen A, Chatonnet J, Dittmar A, Rouanet JL (1985) Potentiated muscular thermogenesis in cold-acclimated muscovy duckling. American Journal of Physiology-Regulatory, Integrative and Comparative Physiology 249:R533-R538.
Bautista DM, Siemens J, Glazer JM, Tsuruda PR, Basbaum Al, Stucky CL, Jordt SE, Julius D (2007) The menthol receptor TRPM8 is the principal detector of environmental cold. Nature 448:204-208

Baxter EM, Jarvis S, D'Eath RB, Ross DW, Robson SK, Farifh M, Nevison IM, Lawrence AB, Edwards SA (2008) Investigating the behavioural and physiological indicators of neonatal survival in pigs. Theriogenology 69:773783.

Baxter EM, Jarvis S, Sherwood L, Robson SK, Ormandy E, Farifh M, Smurthwaite KM, Roehe R, Lawrence AB, Edwards SA (2009) Indicators of piglet survival in an outdoor farrowing system. Livestock Science 124:266276.

Baxter EM, Lawrence AB, Edwards SA (2011) Alternative farrowing systems: design criteria for farrowing systems based on the biological needs of sows and piglets. Animal 5:580-600.

Berthon D, Herpin P, Duchamp C, Dauncey MJ, Le Dividich J (1993) Modification of thermogenic capacity in neonatal pigs by changes in thyroid status during late gestation. Journal of Developmental Physiology 19:253261.

Berthon D, Herpin P, Le Dividich J (1994) Shivering thermogenesis in the neonatal pig. Journal of Thermal Biology 19:413-418.

Berthon D, Herpin P, Le Dividich J (1995) Shivering is the main thermogenic mechanism in cold-exposed newborn pigs. Proceedings of the Nutrition Society 54:55-87.

Bertoni A, Napolitano F, Mota-Rojas D, Sabia E, Alvarez-Macias A, MoraMedina P, Morales CA, Berdugo GJA, Guerrero-Legarreta I (2020a) Similarities and differences between river buffaloes and cattle: health, physiological, behavioural and productivity aspects. Journal of Buffalo Science 9:92-109. DOI: https://doi.org/10.6000/1927-520X.2020.09.12

Bertoni A, Mota-Rojas D, Álvarez-Macias A, Mora-Medina P, GuerreroLegarreta I, Morales-Canela A, Gómez-Prado J, José-Pérez N, MartínezBurnes J (2020b) Scientific findings related to changes in vascular microcirculation using infrared thermography in the river buffalo. Journal of Animal Behaviour and Biometeorology 8:288-297.

Boon CR (1981) The effect of departures from lower critical temperature on the group postural behaviour of pigs. Animal Science 33:71-79.

Bruins AA, Kistemaker KRJ, Boom A, John HG, Klaessens M, Verdaasdonk RM, Boer C (2018) Thermographic skin temperature measurement compared with cold sensation in predicting the efficacy and distribution of epidural anesthesia. Journal of Clinical Monitoring and Computing 32:335-341.

Caldara F, dos Santos L, Machado S, Moi M, de Alencar Nääs I, Foppa L, Garcia RG, de Kássia Silva dos Santos R (2014) Piglets' surface temperature change at different weights at birth. Asian-Australasian Journal of Animal Sciences 27:431-438.

Casas-Alvarado A, Mota-Rojas D, Hernández-Ávalos I, Mora-Medina P, Olmos-Hernández A, Verduzco-Mendoza A, Martínez-Burnes J (2020) Advances in infrared thermography: surgical aspects, vascular changes and pain monitoring in veterinary medicine. Journal of Thermal Biology 92:102664

Charneca R, Nunes JLT, Dividich JL (2010) Body composition and blood parameters of newborn piglets from Alentejano and conventional (Large White x Landrace). Spanish Journal of Agricultural Research 8: 317-325

Close WH (1992) Thermoregulation in piglets: environmental and metabolic consequences. British Society of Animal Production- Occasional Publication 15:25-33.

Curtis SE (1974) Responses of the piglet to perinatal stressors. Journal Animal Science 38:1031-1036

Dauncey MJ, Wooding FB, Ingram DL (1981) Evidence for the presence of brown adipose tissue in the pig. Research in Veterinary Science 31:76-81.

De Roth L, Downie HG (1976) Evaluation of viability of newborn swine. The Canadian Veterinary Journal 17:275-279.

Devillers N, Farmer C, Le Dividich J, Prunier A (2007) Variability of colostrum yield and colostrum intake in pigs. Animal 1:1033-1041.

Devillers N, Le Dividich J, Prunier A (2011) Influence of colostrum intake on piglet survival and immunity. Animals 5:1605-1612.

English PR (1993) Factors affecting neonatal piglet losses and management practices to minimize such losses. The Veterinary Annual. 33:107-119. 
Guerrero-Legarreta I, Napolitano F, Cruz-Monterrosa RG, Mota-Rojas D, Mora-Medina P, Ramírez-Bribiesca E, Bertoni A, Berdugo GJ, Braghieri A (2020) A River buffalo meat production and quality: sustainability, productivity, chemical composition and sensory properties. Journal of Buffalo Science 9:159-169.

Haverkamp FJC, Giesbrecht GG, Tan ECTH (2018) The prehospital management of hypothermia An up-to-date overview. Injury 49:149-164.

Herpin P, Barre H (1989) Loose-coupled subsarcolemmal mitochondria from muscle Rhomboideus in cold-acclimated piglets. Comparative Biochemistry and Physiology B, Comparative biochemistry 92:59-65.

Herpin P, Damon M, Le Dividich J (2002) Development of thermoregulation and neonatal survival in pigs. Livestock Production Science 78:25-45.

Herpin P, Le Dividich J, Berthon D, Hulin J (1994) Assessment of thermoregulatory and postprandial thermogenesis over the first 24 hours after birth in pigs. Experimental Physiology 79:1011-1019.

Herpin P, Le Dividich J (1995) Thermoregulation and the environment. In: Varley MA (Ed) The Neonatal Pig: Development and Survival. CAB International, Wallingford, pp 57-95.

Houška L, Wolfová M, Nagy I, Csörnyei Z, Komlósi I (2010) Economic values for traits of pigs in Hungary. Czech Journal of Animal Science 55:139-148.

Huggins J, Rakobowchuk M (2018) Utility of lacrimal caruncle infrared thermography when monitoring alterations in autonomic activity in healthy humans. European Journal of Applied Physiology 119:531-538.

Jensen T, Pedersen L, Jorgensen E (2011) Hypothermia in neonatal piglets. Journal Animal Science 89:2073-2085.

Kammersgaard T, Malmkvist J, Pedersen L (2013) Infrared thermography-a non-invasive tool to evaluate thermal status of neonatal pigs based on surface temperature. Animal 7:2026-2034.

Kammersgaard TS, Pedersen LJ, Jørgensen E (2011) Hypothermia in neonatal piglets: Interactions and causes of individual differences. Journal of Animal Science 89:2073-2085.

Kelley KW (1985) Immunological consequences of changing environmental stimuli. In: Moberg GP (ed) Animal Stress, American Physiological Society, Bethesda, pp. 193.

Küls N, Blissitt KJ, Shaw DJ, Schöffmann G, Clutton RE (2017) Thermography as an early predictive measurement for evaluating epidural and femoralsciatic block success in dogs.Veterinary Anaesthesia and Analgesia 44:11981207

Le Dividich J, Herpin P (1994) Effects of climatic conditions on the performance, metabolism and health status of weaned piglets: a review. Livestock Production Science 38:79-90.

Le Dividich J, Rooke JA, Herpin P (2005) Nutritional and immunological importance of colostrum for the new-born pig. Journal of Agricultural Science 143:469-485.

Little AG, Seebacher F (2013) Thyroid hormone regulates muscle function during cold acclimation in zebrafish (Danio rerio). The Journal of Experimental Biology 216:3514-3521

Lossec G, Herpin P, Le Dividich J (1998) Thermoregulatory responses of the newborn pig during experimentally induced hypothermia and rewarming. Experimental Physiology 83: 667-678.

Malmkvist J, Damgaard BM, Pedersen L, X Jørgensen E, Thodberg K, Chaloupková H, Bruckmaier RM (2009) Effects of thermal environment on hypothalamic-pituitary-adrenal axis hormones, oxytocin, and behavioral activity in periparturient sows. Journal Animal Science 87:2796-2805.

Malmkvist, J, Pedersen LJ, Damgaard BM, Thodberg K, Jørgensen E, Labouriau R (2006) Does floor heating around parturition affect the vitality of piglets born to loose housed sows? Applied Animal Behaviour Science 99:88-105.

Melišová M, Illmann G, Chaloupková H, Bozděchová B (2014) Sow postural changes, responsiveness to piglet screams, and their impact on piglet mortality in pens and crates. Journal of Animal Science 92:3064-3072.

Morrison SF (2016) Central control of body temperature. F1000Research. doi:10.12688/f1000research.7958.1

Morrison SF, Madden CJ (2014) Central Nervous System Regulation of Brown Adipose Tissue. Comprehensive Physiology 4:1677-1713.
Martínez-Burnes J, Mota-Rojas D, Villanueva-García D, Ibarra-Rios D, Lezama-García K, Barrios-García H, López-Mayagoitia A (2019) Invited review: Meconium aspiration syndrome in mammals. CAB Reviews 14:1-12. Mota-Rojas D (1996) Intensive therapy in the hypothermic newborn piglet. Thesis to obtain the Veterinarian degree. Universidad Autónoma Metropolitana p. 87.

Mota-Rojas D, Ramírez-Necoechea R (1996) Dead piglets and losses for the pig farmer. AgroNegocios 18:2-11.

Mota-Rojas D, Martinez-Burnes J, Trujillo-Ortega ME, Alonso-Spilsbury M, Ramirez-Necoechea R, Lopez-Mayagoitia A (2002) Effect of oxytocin treatment in sows on umbilical cord morphology, meconium staining, and neonatal mortality of piglets. American Journal of Veterinary Research 63:1571-1574.

Mota-Rojas D, Rosales AM, Trujillo ME, Orozco H, Ramírez R, AlonsoSpilsbury M (2005a) The effects of vetrabutin chlorhydrate and oxytocin on stillbirth rate and asphyxia in swine. Theriogenology 64:1889-1897.

Mota-Rojas D, Nava-Ocampo AA, Trujillo-Ortega ME, Velázquez-Armenta $Y$, Ramírez-Necoechea R, Martínez-Burnes J (2005b) Dose minimization study of oxytocin in early labor in sows: uterine activity and fetal outcome. Reproductive Toxicology 20:255-259.

Mota-Rojas D, Martinez-Burnes J, Trujillo ME, Lopez A, Rosales AM, Ramírez R., Orozco H, Merino A, Alonso-Spilsbury M (2005c) Uterine and fetal asphyxia monitoring in parturient sows treated with oxytocin. Animal Reproduction Science 86:131-141.

Mota-Rojas D, Martinez-Burnes J, Alonso-Spilsbury ML, Lopez A, RamirezNecoechea R, Trujillo-Ortega ME, Medina-Hernandez FJ, Albores-Torres V, Loredo-Osti J (2006) Meconium staining of the skin and meconium aspiration in porcine intrapartum stillbirths. Livestock Science 102:155-162.

Mota-Rojas D, Alonso-Spilsbury M, Ramírez-Necoechea R, Moles L, González-Lozano M (2008) Involved factors in the immune response of neonatal pigs. In: Mota-Rojas D, Nava-Ocampo AA, Villanueva-García D, Alonso-Spilsbury M (Eds) Animal Perinatology: Clinical and Experimental Approaches, 1st edn. BM Editores Press, Mexico, pp. 443-454.

Mota-Rojas D, Orozco H, Villanueva-Garcia D, Suarez X, Hernandez R, Roldán $P$, Trujillo-Ortega ME (2011) Foetal and neonatal energy metabolism in pigs and humans: a review. Veterinarni Medicine 56:215-225.

Mota-Rojas D, Martínez-Burnes J, Villanueva-García D, Trujillo OME, Orozco H, Lopez A (2012a) Animal welfare in the newborn piglet: a review. Veterinarni Medicine 57:338-349.

Mota-Rojas D, Villanueva-García D, Hernández R, Martínez-Rodríguez R, Mora-Medina P, González B, Sánchez M, Trujillo-Ortega ME (2012b) Assessment of the vitality of the newborn: an overview. Science Research and Essays 7:712-718.

Mota-Rojas D, Fierro R, Roldan P, Orozco H, González LM, Martínez R., García R, Mora P, Flores S, Sánchez M, Ramírez R (2015) Outcomes of gestation length in relation to farrowing performance in sows and daily weight gain and metabolic profiles in piglets. Animal Production Science 55:93-100.

Mota-Rojas D, López A, Muns R, Mainau E, Martínez-Burnes J (2016) Welfare newborn pig. In: Mota-Rojas D, Velarde-Calvo A, Huertas-Canen S, Cajíao MN (Eds) Animal Welfare, A Global Vision in Ibero-America]. Bienestar Animal una Visión Global en Iberoamérica, 3rd edn. Elsevier, Barcelona, pp. 51-62.

Mota-Rojas D, López A, Martínez-Burnes J, Muns R, Villanueva-García D, Mora-Medina $P$, González-Lozano $M$, Olmos-Hernández A, RamírezNecoechea R (2018) Invited review: Is vitality assessment important in neonatal animals? CAB Reviews 13:1-13.

Mota-Rojas D, Napolitano F, Bertoni A, Gómez PJ, Mora-Medina P, CruzMonterrosa R, Álvarez-Macías A, Pérez NJ, Guerrero-Legarreta I (2020a) Thermal biology in river buffalo in the humid tropics: neurophysiological and behavioral responses. Journal of Animal Behaviour and Biometeorology 9:2103.

Mota-Rojas D, Broom DM, Orihuela A, Velarde A, Napolitano N, AlonsoSpilsbury M (2020b) Effects of human-animal relationship on animal productivity and welfare. Journal of Animal Behaviour and Biometeorology 8:196-205.

Mota-Rojas D, Olmos-Hernández A, Verduzco-Mendoza A, Lecona-Butrón $\mathrm{H}$, Martínez-Burnes J, Mora-Medina P, Gómez-Prado PJ, Orihuela A (2020c) 
Infrared thermal imaging associated with pain in laboratory animals. Experimental Animals 70: (Accepted).

Mount LE (1963) Environmental temperature preferred by the young pig. Nature 199:1212-1213.

Mount LE (1967) The heat loss from new-born pigs to the floor. Research in Veterinary Science 8:175-186.

Mrowka R, Reuter S (2016) Thermoregulation. Acta Physiologica 217:3-5.

Muns R, Nuntapaitoon M, Tummaruk P (2016) Non-infectious causes of preweaning mortality in piglets. Livestock Science 184:46-57.

Muns VR (2013) Welfare and management strategies to reduce preweaning mortality in piglets. Dissertation, Facultat de veterinária de Barcelona.

Nakamura K, Morrison SF (2008) A thermosensory pathway that controls body temperature. Nature Neuroscience 11:62-71.

Nuntapaitoon M, Tummaruk P (2015) Piglet preweaning mortality in a commercial swine herd in Thailand. Tropical Animal Health and Production 47:1539-1546.

Pedersen LJ, Berg P, Jorgensen G, Andersen IL (2011) Neonatal piglet traits of importance for survival in crates and indoor pens. Journal Animal Science 89:1207-1218.

Periasamy M, Herrera JL, Reis FCG (2017) Skeletal Muscle Thermogenesis and Its Role in Whole Body Energy Metabolism. Diabetes and Metabolism Journal 41:327-336.

Pitoni S, Sinclair HL, Andrews PJ (2011) Aspects of thermoregulation physiology. Current Opinion in Critical Care 17:115-121.

Quesnel H, Farmer C, Devillers N (2012) Colostrum intake: Influence on piglet performance and factors of variation. Livestock Science 146:105-114.

Quesnel H, Farmer C (2019) Review: nutritional and endocrine control of colostrogenesis in swine. Animal 13:s26-s34.

Romanovsky AA (2018) The thermoregulation system and how it works. Handbook Clinical Neurolgy 156:3-43.

Rooke J, Bland I (2002) The acquisition of passive immunity in the new-born piglet. Livestock Production Science 78:13-23.

Rowland AL, Bal NC, Periasamy M (2014) The role of skeletal-muscle-based thermogenic mechanisms in vertebrate endothermy. Biological Reviews of the Cambridge Philosophical Society 90:1279-1297.
Shankar B, Madhusudhan HS, Harish DB (2009) Preweaning mortality in pigcauses and management. Veterinary World 2:236-239.

Sosnowski P, Mikrut K, Krauss H (2015) Hypothermia-mechanism of action and pathophysiological changes in the human body. Postepy Higieny I Medycyny Doświadczalnej 69:69-79

Stanton HGL, Brown J, Mueller RL (1973) Interrelationships between maternal and neonatal factors and thermoregulation in fasted neonatal swine (Sus domesticus). Comparative Biochemistry and Physiology 44:97105.

Svendsen JL, Svendsen S, Bengtsson AC (1986) Reducing perinatal mortality in swine. In: Leman AD, Straw BE, Glock RD, Penny RHC, Scholl E (ed) Diseases of Swine 6th edn. lowa State University Press, Ames, pp. 813-824.

Tan CL, Knight ZA (2018) Regulation of Body Temperature by the Nervous System. Neuron 98:31-48.

Terrien J, Perret M, Aujard F (2011) Behavioral thermoregulation in mammals: a review. Frontiers in Bioscience16:1428-1444.

Theil P, Lauridsen C, Quesnel H (2014) Neonatal piglet survival: impact of sow nutrition around parturition on fetal glycogen deposition and production and composition of colostrum and transient milk. Animal 8:1021-1030.

Trayhurn P, Temple NJ, Van Aerde J (1989) Evidence from immunoblotting studies on uncoupling protein that brown adipose tissue is not present in the domestic pig. Canadian Journal Physiology and Pharmacology 67:1480-1485.

Tuchscherer M, Puppe B, Tuchscherer A, Tiemann U (2000) Early identification of neonates at risk: traits of newborn piglets with respect to survival. Theriogenology. 54:371-388.

Vasdal G, Østensen I, Melišová M, Bozděchová B, Illmann G, Andersen IL (2011) Management routines at the time of farrowing-effects on teat success and postnatal piglet mortality from loose housed sows. Livestock Science 136:225-231.

Vasdal G, Wheeler E, Bøe K (2009) Effect of infrared temperature on thermoregulatory behaviour in suckling piglets. Animal 3:1449-1454.

Wu WZ, Wang XQ, Wu GY, Kim SW, Chen F, Wang JJ (2010) Differential composition of proteomes in sow colostrum and milk from anterior and posterior mammary glands. Journal of Animal Science 88:2657-2664. 